\title{
ARTICLE
}

\section{Response to a High-Altitude Earthquake: The Yushu Earthquake Example}

\author{
Jifu Liu ${ }^{1,2, *}$, Yida Fan ${ }^{3}$, and Peijun $\mathrm{Shi}^{4}$ \\ ${ }^{1}$ Key Laboratory of Environmental Change and Natural Disasters, Ministry of Education of China, Beijing Normal University, \\ Beijing 100875, China \\ ${ }^{2}$ Academy of Disaster Reduction and Emergency Management, Ministry of Civil Affairs and Ministry of Education, Beijing 100875, China \\ ${ }^{3}$ National Disaster Reduction Center, Ministry of Civil Affairs, Beijing 100053, China \\ ${ }^{4}$ State Key Laboratory of Earth Surface Processes and Resource Ecology, Beijing Normal University, Beijing 100875, China
}

\begin{abstract}
At 07:49, 14 April 2010, the Yushu Tibetan Autonomous Prefecture of Qinghai Province on the Qinghai-Tibet Plateau, China was struck by a magnitude 7.1 earthquake, with the epicenter located at $33.1^{\circ} \mathrm{N}$ and $96.7^{\circ} \mathrm{E}$ and at an altitude of $4300 \mathrm{~m}$, and an epicentral intensity of Modified Mercalli scale IX. It was the first strong earthquake that struck the high-altitude, hypoxia-prone Tibetan plateau primarily inhabited by ethnic minorities since the founding of the People's Republic of China, which has caused a huge loss of lives and property and adversely impacted the economic and social development of the area. The 2010 Yushu Earthquake was an earthquake disaster with the greatest destruction, widest spatial extent, and greatest difficulty for relief efforts in the history of Yushu, involving 19 townships in six counties of the prefecture. As verified by the Ministry of Civil Affairs, Ministry of Public Security, and the Yushu Prefecture Government, the earthquake killed 2698 people and caused government agencies to list 270 missing persons, who were mostly in Jiegu Town of Yushu County. The earthquake also caused a direct economic loss of RMB 44 billion Yuan. The severe environmental conditions in Yushu and limited infrastructural support for disaster relief to remediate the impacts on the earthquake victims were also rare in the history of earthquake disaster relief. This article focuses on the characteristics of the high-altitude Yushu Earthquake assessment and response, and summarizes the experiences and lessons of government and society in responding to this earthquake. The assessment of and response to the Yushu Earthquake will provide helpful references for high plateau earthquake response in the future.
\end{abstract}

Keywords catastrophe assessment and response, hypoxia, Qinghai-Tibet Plateau, Yushu Earthquake

\section{Introduction}

The Yushu Tibetan Autonomous Prefecture is located in the southwestern part of Qinghai Province on the Qinghai-Tibet

\footnotetext{
* Corresponding author. E-mail: liujifu@bnu.edu.cn
}

Plateau, where the three large rivers in China (the Yangtze River, the Yellow River, and the Lancang River) originate. The prefecture has an average altitude of 4000-5000 m. With the river network spreading within the territory, it is known as the "Water Tower of China." With a total area of $267,000 \mathrm{~km}^{2}$ and a population of 283,100 of which 95 percent are Tibetan (about a quarter of the Tibetan population in the province), the prefecture is the most heavily populated by Tibetans within the province. It is mainly a pastoral area and has a relatively mild climate in the eastern part, with limited agricultural areas along the rivers. With a gross domestic product (GDP) of 2.54 billion Yuan and per capita GDP of less than 9000 Yuan (USD 1300) in 2009, the prefecture is a typical povertystricken area in China. Jiegu Town of Yushu County, where the autonomous prefecture government is located, has a permanent population of about 80,000 , which is 35 percent of the total population in the prefecture. Among this urban population, more than 98 percent are Tibetans.

Due to its remote, high-altitude plateau and hypoxia plagued environment and unique social and cultural settings characterized by a very high concentration of ethnic minorities, the experiences gained and lessons learned during the course of emergency response and recovery and reconstruction for this earthquake bear special relevance for regions in western and southwestern China. After the earthquake, the National Commission for Disaster Reduction (NCDR) of China organized experts to visit the earthquake site for scientific study of the earthquake and assessment of the earthquake disaster losses. Two of the three authors of this report, Professor Liu and Dr. Fan, gained direct experience of the Yushu disaster by participation in these studies. After introducing the earthquake event and making a brief assessment of its impact and the national response process, this article discusses and summarizes the experiences and lessons for government, society, and media in the region's earthquake response. 


\section{Basic Information of the Yushu Earthquake}

The Yushu Earthquake developed a distinct rupture structure and caused frequent post earthquake structural activities. The quake area is a high-altitude environment and hypoxia-prone, a condition in which blood and tissue oxygen is abnormally low, adversely affects unadapted individuals who enter these upland areas. Individuals with a blood or tissue oxygen content of only 40 percent of that in plain areas can become seriously ill and experience heart and brain functional problems. Heavy physical activity is a major problem under these conditions. The Yushu Tibetan Autonomous Prefecture is a region with most Tibetan population in China and in its capital city, Jiegu Town, more than 98 percent of the residents are Tibetans. According to field investigation, the buildings in the quake area are of typical Tibetan style with heavy roofs and shallow foundations, causing, in case of any major earthquake, damage to and collapse of houses, which can result in substantial human casualties.

\subsection{Geophysical Background}

Yushu is located in the interior of the Qinghai-Tibet Plateau, with an average altitude of $4300 \mathrm{~m}$. Due to the effect of continual mutual bearing stresses between the Indian Plate and the Euro-Asian Plate, fracture zones are extensively distributed across the region and are very complex. These fracture zones generally run in a northwest-southeast direction, and are associated with frequent earthquake activities (Figure 1).
The Yushu Earthquake occurred on the Ganzi-Yushu Fracture Zone where no major earthquake stronger than magnitude 7 was observed over the past century. The northwest section of this fracture zone had no record of any earthquake (Chen, Ma, and Yang 2010). On 18 and 19 July 2006, three earthquakes struck with a magnitude of 5.0, 5.6, and 5.4, releasing part of the energy aggregated in the area. Due to the energy built up over the following four years, the Yushu Earthquake (a magnitude 7.1 earthquake) eventually took place on the Ganzi-Yushu Fracture Zone between the East Qiangtang Block and the Bayan Kar Block (Figure 1). As of 15:00, 3 December 2010, the China Earthquake Network Center had recorded in total 3358 aftershocks, including 41 aftershocks of over magnitude 3.0 on the Richter scale. Among these, there was one earthquake of magnitude 6.0 6.9, two earthquakes in the 5.0-5.9 range, 10 earthquakes of magnitude 4.0-4.9, and 28 earthquakes of 3.0-3.9 magnitude (Figure 1).

\subsection{Fault Rapture Process}

Using the wave data recorded at 31 seismic stations around the world, Wang (2010) and Qian and Qin (2010) determined that the Yushu Earthquake was centered on an almost vertical left-rotary sliding fault. The quake was characterized by a one-way rupture, a rupture direction from northwest to southeast, a total rupture length of $60 \mathrm{~km}$, and a maximum fault surface displacement of $2.4 \mathrm{~m}$. Wen, Xu, and Zheng (2003) ascertained that on the surface of the Ganzi-Yushu Fracture Zone, there were mainly two areas of intensive sliding:

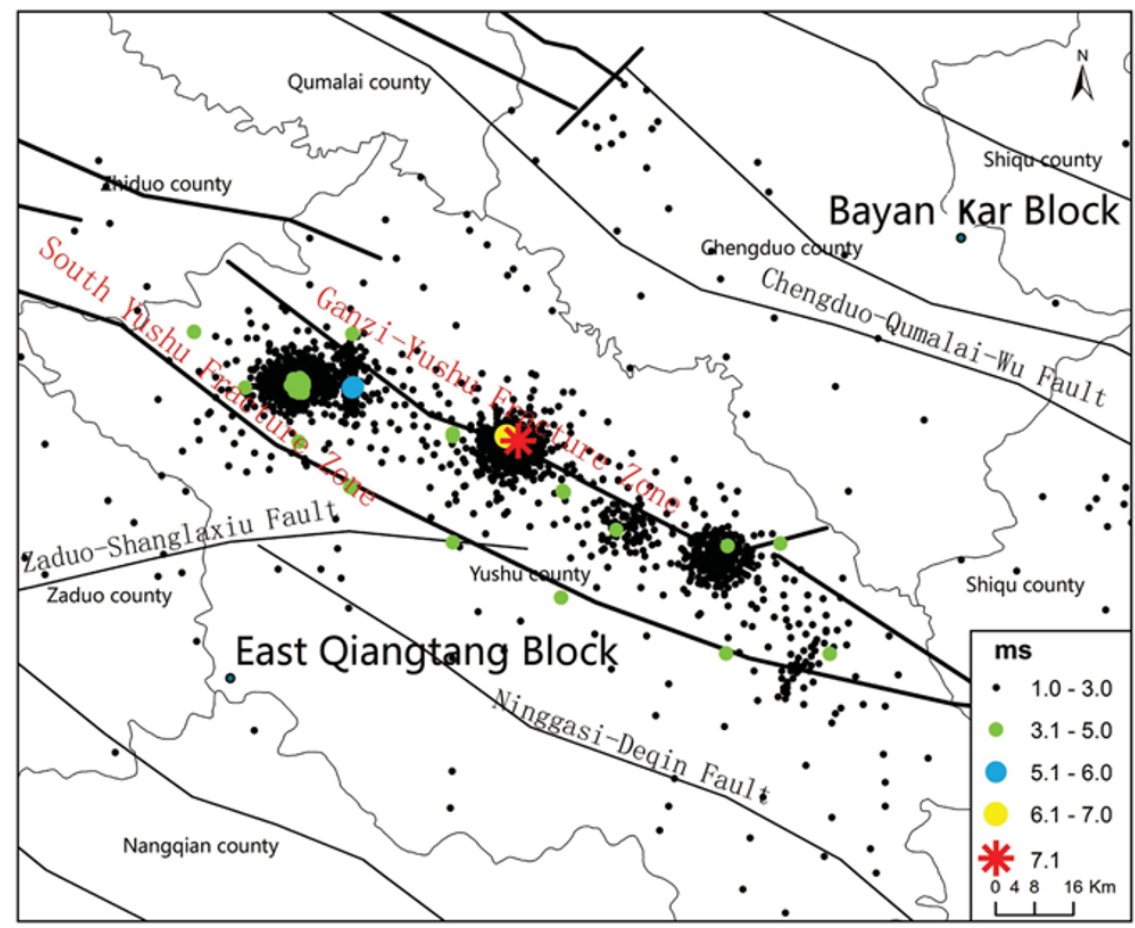

Figure 1. Major active faults and aftershock distribution in the Yushu Earthquake disaster area Source: China Earthquake Administration and Beijing Normal University. 
the first rupture area was located near the epicenter, with a slide of about $2.0 \mathrm{~m}$ and a maximum sliding speed of about $0.9 \mathrm{~m} / \mathrm{s}$; the second rupture area was located, in terms of heading direction, at Jiegu Town, about $10-30 \mathrm{~km}$ away from the epicenter (Figure 1).

\subsection{Post-Quake Tendency Estimation}

As a whole, under the joint effect of the northeastward bearing stress field and southeastward tensile stress field, Qinghai-Tibet Plateau formed, in the direction of tensile stress, a series of arc fractures that are nearly parallel and among which are some deep and big fractures. These fracture zones, due to their strong seismic activities, were considered to be the boundary of active blocks. With the Indian Plate downthrusting northeastward and pressing against the Euro-Asian Plate at a speed of approximately $50-55 \mathrm{~mm} \cdot \mathrm{a}^{-1}$, the internal blocks of the Qinghai-Tibet Plateau were sliding laterally along the boundary fracture zones, causing the Qinghai-Tibet Plateau to move eastward as a whole. Given this background movement, modern seismic activities in the southern section of the Ganzi-Yushu Fracture Zone became obvious, while such activities in the northern section were not strong. According to the results of stress field observations, since 1783 when Yushu was previously struck by an approximately magnitude 7.0 earthquake, the recurrence period of the Yushu Earthquake was estimated at about 200 years (Xu, Di, and Feng 2010; Peng, Ma, and Bai 2006; Ren, Xie, and Liu 2010).

\section{Assessment of the Yushu Earthquake Disaster Losses}

Since the 2008 Wenchuan Earthquake, ${ }^{i}$ China has established a " $2+1$ " earthquake catastrophe assessment model (NCDR 2008) based on (1) statistical data of losses reported by the local government of a disaster area; (2) professional survey and assessment at the earthquake site; and (3) the local government and its disaster management department and other relevant departments' collective consultation for verifying the final earthquake disaster losses. Considering the remote location and severe natural environmental condition (a high-altitude, hypoxia-prone plateau habitat) of the Yushu Earthquake area, its large disaster-affected area, and various ethnic minority populations, the Chinese government established a " $3+1$ " assessment model for this earthquake.

Based on the conventional " $2+1$ " model, the " $3+1$ " model added high-resolution remote sensing data analysis to meet the demand for earthquake assessment in such a special and remote region. Upon the occurrence of this earthquake, the NCDR immediately sent out an expert team to the site for field survey and assessment and for collaboration with the central remote sensing assessment team in order to provide rapid on-site verification of the results obtained from the analyses of the remote sensing images. This close linkage between ground checking and image analysis accelerated assessment of the Yushu Earthquake's extent and impact. Because the earthquake had a large disaster-affected area and was highly difficult for disaster relief to reach, promptly providing the Chinese government with accurate information for planning relief, recovery, and reconstruction was essential.

\subsection{Remote Sensing Assessment of Yushu Earthquake Losses}

Two mechanisms exist for rapid disaster planning and response: Environment and Disaster Monitoring and Forecasting Small Satellite Constellation (EDMFSSC) and International Charter on Space and Major Disasters (ICSMD). The EDMFSSC mechanism permits appropriate agencies to access remote sensing images held by the National Disaster Reduction Center of China (Satellite Disaster Reduction Application Center, Ministry of Civil Affairs). The ICSMD enables disaster planners to get free satellite data from ICSMD's members to timely monitor and evaluate disaster loss.

Through these mechanisms, the Ministry of Civil Affairs (MCA) and NCDR of China promptly assembled 496 satellite images and aerial photographs in the disaster area after the quake. Jiegu Town was divided into grids and encoded. Through analyzing these assembled imageries and aerial photographs, disaster impacts such as damages to housing in Jiegu Town were evaluated (Figure 2). Additionally, through a new field disaster information collection system, field survey personnel sent back the required information within a few minutes. Functionally, a seamless link was established between in-field disaster information retrieval and remote sensing data analysis to assist planners operating at local and national scales in their evaluation of disaster impacts. This effectively ensured the accuracy of the remote-sensing monitoring results and improved the speed and effectiveness of disaster relief.

According to image interpretation and calculation, in the urban area of Jiegu Town, the total square footage of collapsed and damaged houses due to this disaster amounted to $4.326 \times 10^{6} \mathrm{~m}^{2}$, including single-storey houses of 2.937 $\times 10^{6} \mathrm{~m}^{2}$ and multi-storey buildings of $1.389 \times 10^{6} \mathrm{~m}^{2}$, which is 68 percent and 32 percent of the total areas of the corresponding building types.

In Jiegu Town, 1000 Yuan $\cdot \mathrm{m}^{-2}$ were applied to calculate the economic losses due to complete collapse and substantial damage of single-storey houses, 1800 Yuan $\cdot \mathrm{m}^{-2}$ for complete collapse and substantial damage of multi-storey buildings, 500 Yuan $\mathrm{m}^{-2}$ for moderate and light damage of single-storey houses, and 900 Yuan $\cdot \mathrm{m}^{-2}$ for moderate and light damage of multi-storey buildings. Based on these calculations and the image interpretation result, the direct economic losses arising from collapsed and damaged houses in the disaster area amounted to 4.976 billion Yuan, including the direct economic loss of 4.516 billion Yuan resulting from the complete 


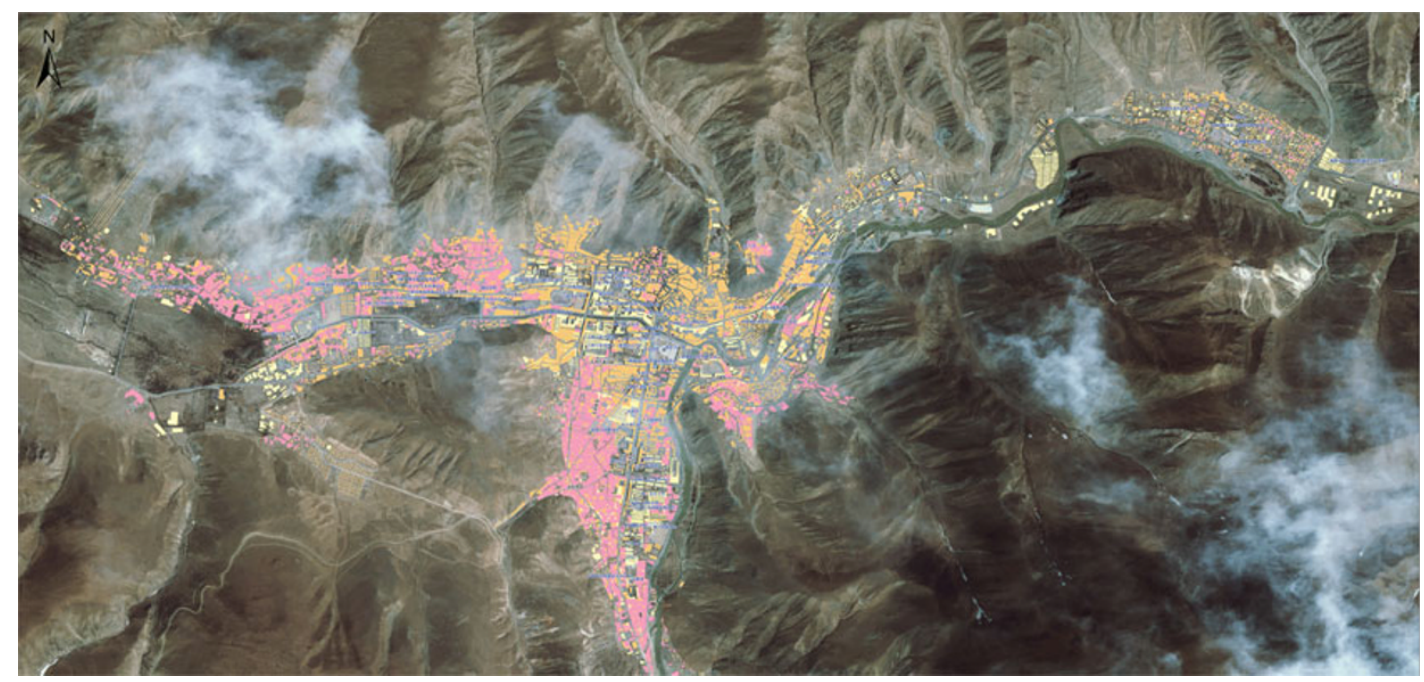

Figure 2. Remote-sensing assessment of collapsed and damaged houses in Jiegu Town (Pink identifies completely destroyed buildings, orange reflects severely damaged buildings, and yellow indicates slightly damaged buildings. The scale is $1: 4000)$

Source: National Disaster Reduction Center of China (Satellite Disaster Reduction Application Center, Ministry of Civil Affairs) and Beijing Normal University.

collapse and substantial damage to houses. This result is in agreement with the field survey and assessment result of the China Earthquake Administration (CEA).

\subsection{Integrated Assessment of Disaster Losses due to the Yushu Earthquake}

Loss statistical indicators of the Yushu Earthquake largely conformed to those used for the Wenchuan Earthquake. Considering that the area has a high concentration of ethnic minority Tibetan population and is the source area of three of the most important rivers of China, we included two additional aspects in the loss assessment: religious assets and nature reserves. The statistical statement included 13 categories, including losses of rural housing, losses of urban residential and non-residential buildings, agricultural losses, industrial losses, infrastructure losses, among others. In general, the statistical statement was prepared with the aim of representing the major natural and social losses in the disaster area caused by this earthquake.

Since local governments often lack the necessary technical means to accurately assess the impacts in disasters of this scale, and they also have the tendency to exaggerate economic losses resulting from natural disasters, statistical data submitted by local governments are not always reliable and thus must be verified. During the disaster loss assessment of the Yushu Earthquake, the " $3+1$ " model was adopted primarily for this purpose. The Field Survey and Assessment Report of Disaster Losses for the Yushu Earthquake issued by the CEA ${ }^{\text {ii }}$ and the Technical Report on Remote-Sensing Monitoring and Assessment of the Yushu Earthquake prepared by the NCDR ${ }^{\mathrm{iii}}$ are the results of this model.

During the field survey, review of the structural classification of buildings, building costs, and damaged proportion of buildings in the rural and urban areas of the disaster-affected zone reduced overestimation of losses by the local governments. The losses of nature reserves and religious assets were generally not verified and data provided by the local governments were used instead. By cross-checking the results of the local government, CEA, and NCDR assessments, we obtained a preliminary integrated assessment of disaster losses due to the Yushu Earthquake, which was then examined by a joint consultation in the next step of the disaster impact assessment process.

The joint consultation was organized by the Ministry of Civil Affairs and attended by the Qinghai Provincial Government, Sichuan Provincial Government, China Earthquake Administration, Ministry of Land and Resources, Ministry of Housing and Urban-Rural Development, Ministry of Agriculture, Ministry of Education, State Administration of Religious Affairs, National Bureau of Statistics, State Bureau of Surveying and Mapping, Ministry of Finance, National Development and Reform Commission, and other relevant government departments. The joint consultation was mainly an interrogation of the scientific base and accuracy of the verification methods used to establish disaster losses and focused on the credibility of the assessment results. After three rounds of joint consultation, the final integrated assessment for disaster losses of the Yushu Earthquake was obtained. The direct economic loss of the Yushu Earthquake was estimated at RMB 44 billion Yuan, including RMB 43.65 billion Yuan for Qinghai Province and RMB 350 million Yuan for Sichuan Province (Figure 3). The highest loss occurred in the infrastructure category, including damages to roads, bridges, and other transportation facilities and municipal water, hydropower, communication facilities, among others. The second highest loss was related to damages to urban residential and non-residential buildings. Damages to rural housing constitute a relatively small share of the losses. 


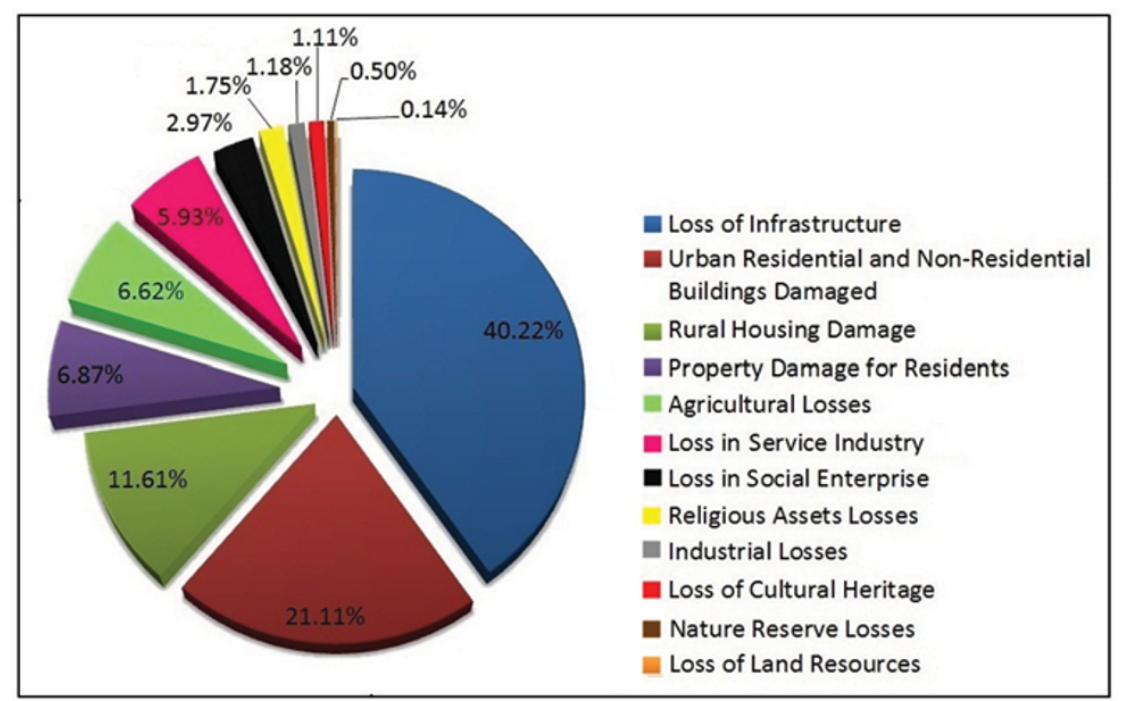

Figure 3. Assessment results of the Yushu Earthquake disaster losses

Source: National Disaster Reduction Center of China (Satellite Disaster Reduction Application Center, Ministry of Civil Affairs) and Beijing Normal University.

\section{Yushu Earthquake Response and Recovery and Reconstruction}

The Yushu Earthquake disaster area is characterized by severe natural conditions, vulnerable ecological environment, inadequate communication facilities, poor conditions for construction, and high concentration of ethnic minorities. Thus the response to this earthquake and the recovery and reconstruction are particularly difficult.

\subsection{Characteristics of the Yushu Earthquake Disaster Area}

The Yushu Earthquake disaster area is characterized by the following:

Severe natural conditions: The disaster area is located in the source area of the "three rivers" in the northern QinghaiTibet Plateau, with an average altitude of over $4000 \mathrm{~m}$, cold climate, high variation of temperature between day and night, a short frost-free period, and a high hypoxia risk for unadapted outsiders causing heart and brain problems, altitude sickness, extreme tiredness and low energy levels, and shortness of breath that impact relief and reconstruction workers. Hypoxia even adversely impacts search dogs brought in to hunt for people trapped in the rubble of collapsed buildings. As the annual effective construction period is only five months, it is very difficult to carry out the reconstruction of earthquake-damaged houses.

Vulnerable ecological environment: A major portion of the area is part of the alpine meadow ecological system, which is extremely vulnerable to disruption. Typical plants in this habitat have a short growing season and the area is prone to soil and water erosion. The system's resistance to external stresses is weak, and it is extremely difficult for the system to recover quickly from any damage.

Inadequate communication facilities: The disaster area is vast, with a low density highway network and poor road conditions. Communication with the outside world is difficult. The only main transport channels are the National Highway 214 (G214) and the Provincial Highway 307 (S307) (Figure 4). The transportation distance to and from eastern and central China is long and the cost is high.

Poor conditions for construction: The urban topography is rugged with limited construction areas having moderate to gentle slopes. Steep slopes ensue a high degree of difficulty for the organization of large-scale construction and a low accessibility of construction materials.

Shortage of building resources: In this area important building materials basically depend on outsourcing. Professional talents of design, construction, and management are inadequate and professional construction teams able to operate in the plateau environment are in short supply and limited in local experience.

Weak economic base: The local economy mainly depends on animal husbandry on natural grassland. The pastoral sector is augmented by a simple industrial structure. The area has limited financial resources available to local governments, low income levels for farmers and herdsmen, widespread poverty, and a low capacity for self-recovery.

High concentration of ethnic minorities: The proportion of ethnic minorities in the disaster area is over 98 percent, while the proportion of Tibetans is over 93 percent. The Yushu Tibetan Autonomous Prefecture has abundant relics of ethnic culture and unique regional characteristics of Tibetan cultural traditions. 


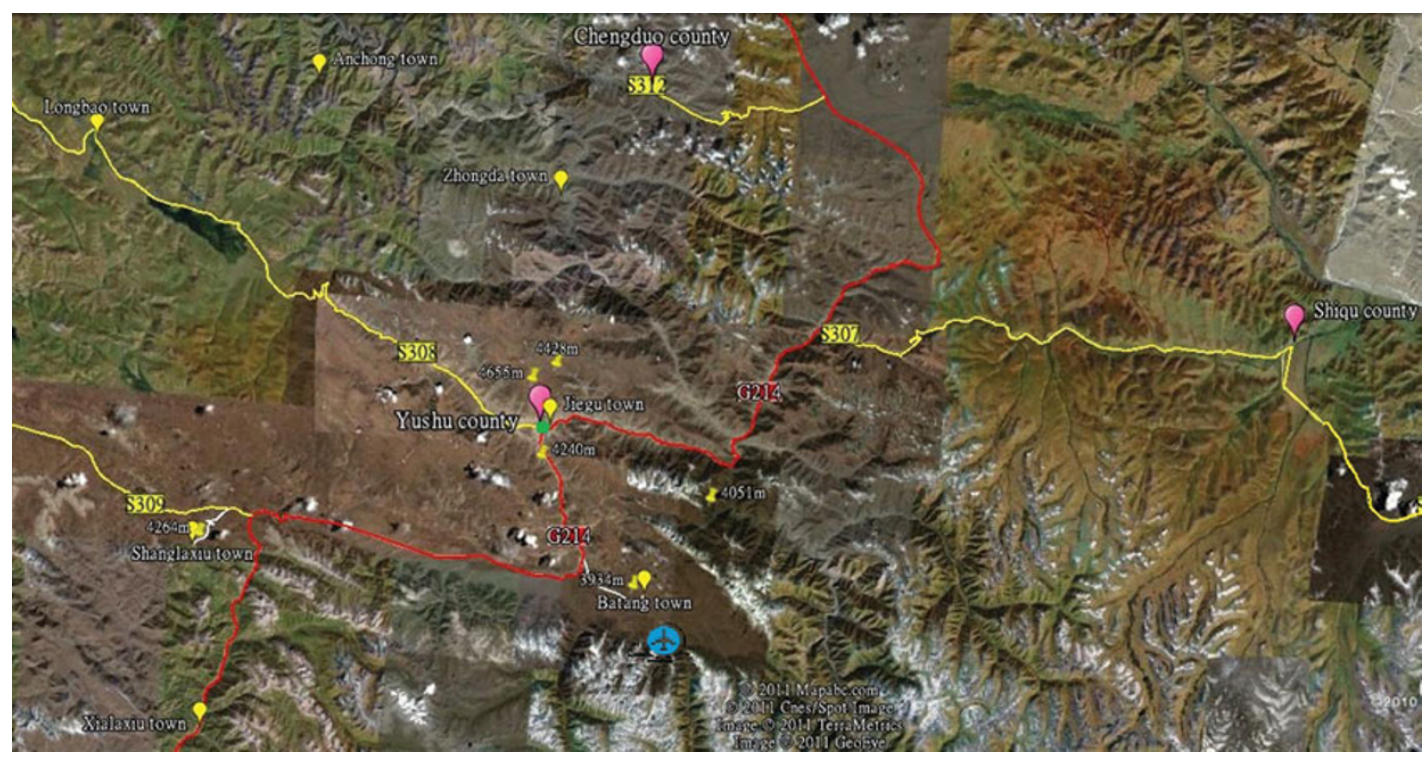

Figure 4. Road network of the Yushu Earthquake area

Source: Google and Beijing Normal University.

Profound religious influence: The disaster area is home to various schools of Tibetan Buddhism, with many temples, monks, and believers. Religious influence is pervasive.

Due to these factors, the response to the Yushu Earthquake and the recovery and reconstruction of the disasteraffected area faced great difficulties and challenges (Figure 5; Figure 6).

\subsection{Yushu Earthquake Response}

After the Wenchuan Earthquake, China has improved its emergency response capacity and has gradually established a complete nationwide response system based on the national conditions of China and with Chinese characteristics. The central government has set up six major emergency response mechanisms: disaster emergency response; disaster information release; disaster relief material reserve; disaster early warning, joint consultation, and information sharing; coordination for major disaster rescue and relief; and social mobilization for disaster emergency response (Deng and Liu 2011). Local governments at different levels have also established relevant earthquake response and disaster relief mechanisms. This nationwide response system played an important role in the Yushu Earthquake rescue operation, not only improving the rescue efficiency significantly, but also speeding up the transition from rescue to recovery and reconstruction.

Public participation started to play a role in the response to the Wenchuan Earthquake, and become much more prominent in the response to the Yushu Earthquake. After the Wenchuan Earthquake, the total registered number of foundations, charity associations, and Red Cross organizations involving the general public exceeded 5000. The role of such charity organizations in raising funds for response to disasters has clearly strengthened. As of 31 May 2010, the total donations received in kind and money nationwide for the disaster relief of the Yushu Earthquake amounted to 7.129 billion Yuan. This included 6.44 billion Yuan in cash and 689 million Yuan in kind. The donations received by the MCA amounted to 2.188 billion Yuan (inclusive of the amount rendered by the local authorities of civil affairs); the donations received by the Red Cross Society of China amounted to 1.484 billion Yuan (inclusive of the amount from local Red Cross and 161 million Yuan in kind); the donations received by China Charity Federation amounted to 1.423 billion Yuan (inclusive of the amount from local charity associations); the donations received in cash and kind by the government of Qinghai Province amounted to 1.808 billion Yuan (inclusive of 353 million Yuan in cash from provincial budgets and from regions in non-disaster areas and 505 million Yuan in kind); the donations in cash and kind received by other foundations amounted to 226 million Yuan (inclusive of 23 million Yuan in kind) (Bai 2010).

Of the charity funds raised, the amount contributed by the MCA was only 30.69 percent, while the remaining 69.31 percent was raised by nongovernmental charity institutions (Figure 7). As compared to the Wenchuan Earthquake, the proportion of public donations increased substantially, demonstrating the rapid expansion of public participation in disaster relief. According to the stipulation of the State Council of the People's Republic of China, all the donated funds were distributed by the Qinghai Provincial Government for the recovery and reconstruction in the disaster areas of the Yushu Earthquake.

The media has also played an important role in the response to the Yushu Earthquake. Full coverage of the Yushu Earthquake by the Chinese news media has demonstrated the care and respect of the party and state leaders for the people 

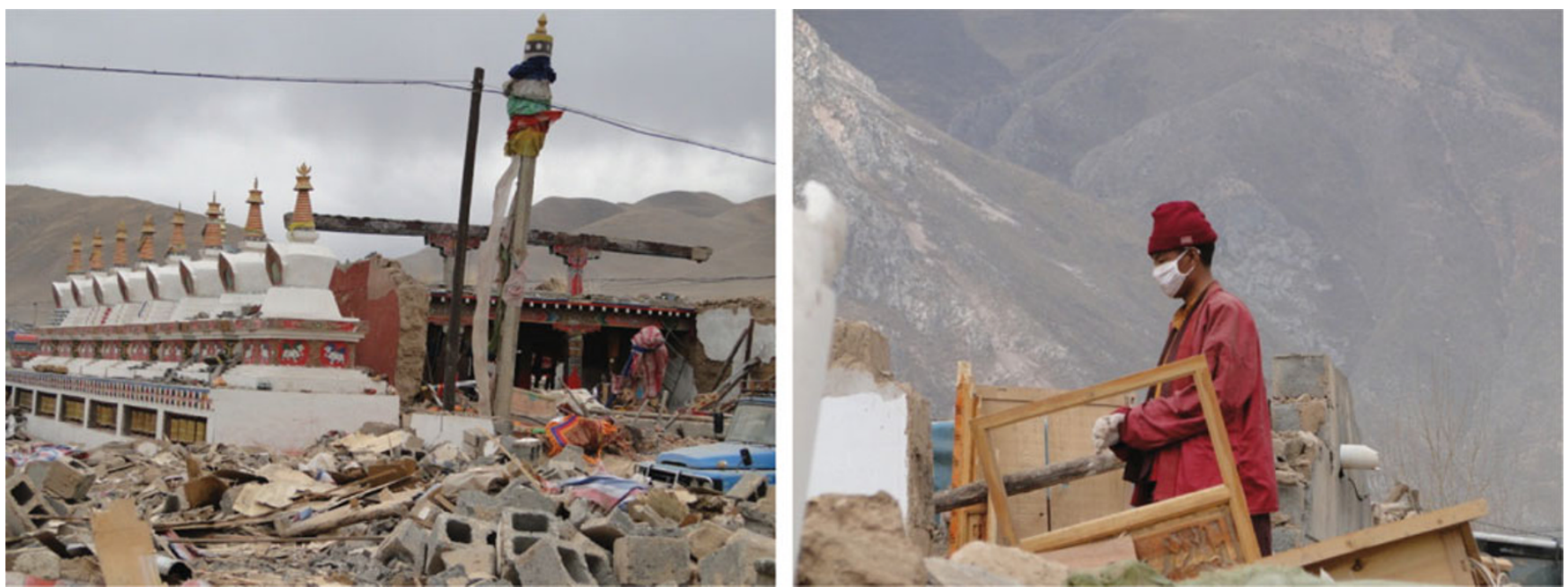

Figure 5. Collapsed Tibetan temple in Jiegu Town (left) and a lama clearing the ruins at home (right) Photographs by Jifu Liu, 19 April 2010.
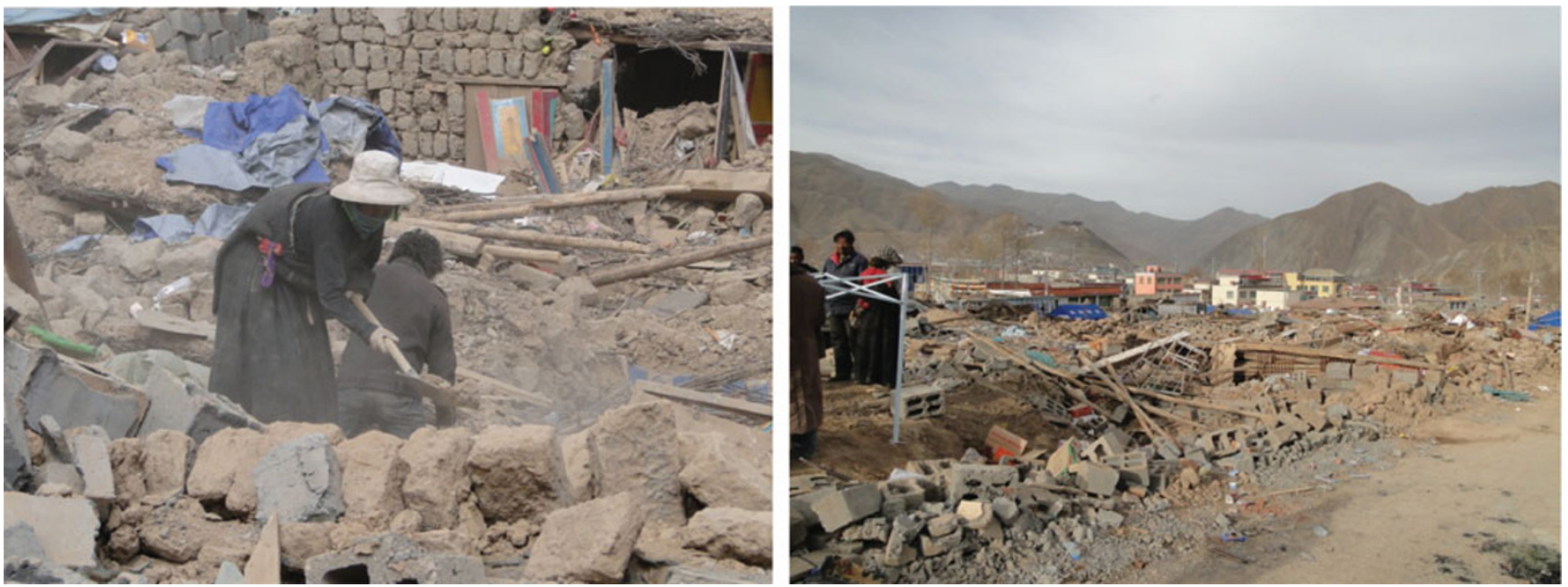

Figure 6. Tibetan disaster victims clearing the ruins (left) and Jiegu Town (right) (the peak in the picture has an altitude of $4700 \mathrm{~m}$ )

Photographs by Jifu Liu, 19 April 2010.

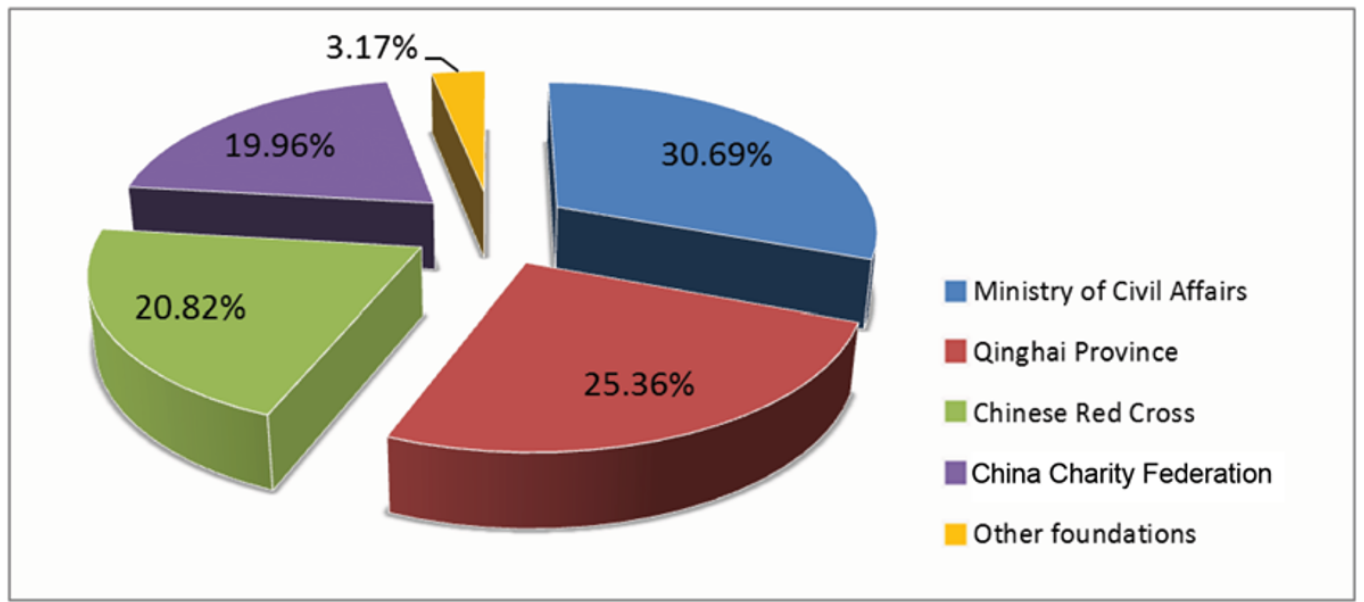

Figure 7. Distribution of funds raised by different organizations for disaster relief of the Yushu Earthquake

Source: National Disaster Reduction Center of China (Satellite Disaster Reduction Application Center, Ministry of Civil Affairs) and Beijing Normal University. 
in the disaster area and kept the public and organizations outside of the area informed of the situation. Coverage by the international media attracted attention globally to the Yushu Earthquake and kept the world informed about the progress of disaster relief in China. The Financial Times, The Wall Street Journal, CNN, Time, Daily Telegraph (UK), and other international media have all shown a high level of concern over the Qinghai Yushu Earthquake.

\subsection{Post-Disaster Recovery and Reconstruction of the Disaster-Affected Area}

With the application of the " $3+1$ " model, the general planning of the Chinese Government, and the support of the people across the country, the disaster area of the Yushu Earthquake moved quickly from the emergency response stage to the recovery and reconstruction stage, creating a unique post-disaster reconstruction model for other remote, high-altitude, and hypoxia-afflicted plateau earthquake areas.

On 21 April 2010, at its eighth full-plenary meeting, the State Council Earthquake Relief Headquarters held a hearing on the report for post-disaster recovery and reconstruction program and actuated all the works for post-disaster recovery and reconstruction; on 24 May 2010, the State Council issued the Guidelines for Carrying out the Post-Disaster Recovery and Reconstruction of the Yushu Earthquake (The State Council of the People's Republic of China 2010a). The State Council set ambitious goals for disaster recovery. It proposed to complete the major tasks of recovery and reconstruction in three years; on 9 June 2010, the State Council approved the General Planning for the Post-Disaster Recovery and Reconstruction of the Yushu Earthquake (The State Council of the People's Republic of China 2010b). Through these planning and well-informed decision-making, the recovery and reconstruction of the disaster area was carried out in an orderly way.

In order to facilitate the implementation of the above planning, a series of economic policies for reconstruction were issued. On 21 April 2010, the People's Bank of China and other relevant government departments issued the Urgent Notice for Carrying Out Financial Services for the Disaster Areas of the Yushu Earthquake (People's Bank of China 2010); on 5 August 2010, the Ministry of Finance and other relevant government departments issued the taxation policies for supporting the post-disaster recovery and reconstruction of the Yushu Earthquake (Ministry of Finance of the People's Republic of China 2010).

Based on the successful experiences in partnership support after the Wenchuan Earthquake, on 20 June 2010, the State Council Earthquake Relief Headquarters arranged a partner assistance program for recovery and reconstruction. According to the terms of this arrangement, the Beijing Municipality, Liaoning Province, and four large state-owned enterprises (China State Construction Engineering Corporation, China Railway Engineering Corporation, China Railway Construction Corporation, and Sinohydro Corporation) took on the partner assistance task for Yushu. By the end of 2010, 298 projects had been commenced, with a total investment of 5.01 billion Yuan. Of all the recovery and reconstruction projects, public service projects such as urban-rural housing, education, and health were defined as priority projects for reconstruction. The construction of schools, hospitals, and residential buildings started the earliest and progressed the fastest, and was the first completed component in the post-disaster reconstruction (Figure 8). In the 19 townships of the six counties in Yushu Prefecture affected by the earthquake, 11,665 houses were built or were under construction for farmers and herders, while some of the farmers and herders already had moved into their new houses in two villages, Cangu and Ganda, as had others in Anchong, Zhongda, Batang, and other townships in the Yushu County. The reconstruction of 13 schools (including the Yushu County No. 1 Public Middle School), the Yushu Prefecture Public Health Service Center, the Tibetan Hospital, and many other projects have been completed and these facilities are expected to be in service in September 2011. As of 14 April 2011, 463 projects had been consigned for planning and design, while the investment for recovery and reconstruction is expected to reach 25.5 billion Yuan in 2011 (Xinhua News Agency 2011).

\section{Experiences and Lessons}

As the first major earthquake striking the remote high-altitude and hypoxia plateau since the founding of the People's Republic of China, the Yushu Earthquake drew a great deal of attention at home and abroad. The Yushu Earthquake response and recovery and reconstruction experiences can be used as a reference for future actions in similar areas.

The Yushu Earthquake disaster relief has five important characteristics. First, the rescue work was highly efficient and coordinated. The State Council immediately established the Earthquake Relief Headquarters after the earthquake, and

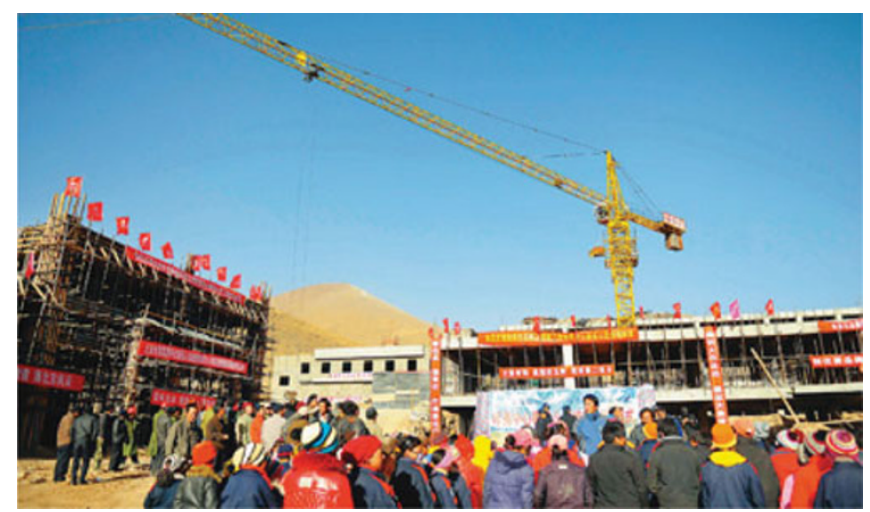

Figure 8. Roof-sealing for a primary school building with the highest altitude in the disaster area (under the partner assistance of Beijing Municipality)

Photograph by Guangyu Wu, Xinhua News Agency, 18 November 2011. 
rescue, medical assistance, and relief goods from the central government and other provinces, regions, and municipalities were continuously delivered to the disaster area. Qinghai Province and Yushu Prefecture also immediately set up headquarters to mobilize provincial and prefectural resources for disaster relief. The national, provincial, and prefectural headquarters and the joint headquarters of the army and the armed police force were allocated different tasks but always operated in close cooperation and coordination with each other and with local authorities and institutions. From the central government to the local governments, the army to the civil society, and the frontline to remote control centers, the whole system operated efficiently and provided strong leadership support for the relief effort.

Second, all parties involved took a human-oriented approach. Governments at all levels focused on the absolute priority of saving lives. Within 72 hours after the quake, 1433 survivors were rescued from the ruins. Every effort was made to treat the injured, with the goal of reducing death and long-term handicaps. Meanwhile, the government made every effort to relocate the disaster-affected population and provide accommodations, food, clean drinking water, medical assistance, and schooling.

Third, the relief work was well-planned. In view of the practical problem of the short suitable season for construction, recovery and reconstruction already had started while the emergency disaster relief was still on-going. By the second day after the earthquake, a group of people were sent to the neighboring Sichuan Province to train for reconstruction. On the seventh day, the provincial communist party committee and government of Qinghai held a meeting on post-disaster reconstruction. As early as the tenth day, the preliminary disaster assessment was concluded and the preparatory work was promptly undertaken for post-disaster reconstruction.

Fourth, the rescue and relief effort was characterized by national unity, religious harmony, and mutual-assistance. After the earthquake, in Yushu Prefecture people of different nationalities shared all necessities for living, helped each other, and strove for self-assistance. Religious persons, especially monks of Tibetan Buddhism, actively participated in rescuing people trapped under collapsed buildings and assisted the government in properly handling the dead bodies, showing a strong solidarity and spirituality. The national and provincial departments of religious affairs extensively mobilized people of different nationalities and religions for active participation in the earthquake disaster relief.

Last, the presence of the communist party members and government officials on the rescue and relief sites provided a powerful organizational assurance for earthquake disaster relief. In the face of the earthquake and aftershocks and the tremendous difficulties these seismic disturbances posed for rescue and relief, the presence of such leadership also provided inspirations and promoted solidarity, and thus positively contributed to the overall effort of disaster relief.

\subsection{Experiences}

There were five major experiences associated with efforts to cope with the Yushu Earthquake:

Successful nationwide response system: The nationwide system established by the Chinese government in responding to major disasters played a remarkable role in responding to the 2008 Wenchuan Earthquake and also a very important role in responding to the Yushu Earthquake. The general architecture of this system proved successful in achieving its goals of rapid and efficient relief and recovery from disaster. Owing to the success of this system, the disaster area of the Yushu Earthquake could promptly move from the emergency response stage to the recovery and reconstruction stage. It demonstrated the leading role of the government in responding to a catastrophe.

Gradually-expanding role of the public: The general public was and remains an important force in responding to the Yushu Earthquake. As compared to the time when the Wenchuan Earthquake struck, public participation in disaster relief in China has gradually expanded. In the emergency rescue phase, as well as through fund raising after the Yushu Earthquake, the general public has demonstrated its very important role as an active participant.

Transparent disaster information publication system: As the relevant information of the Yushu Earthquake was transparently released to the world, the Chinese media won a position as the most important source of reliable information about the disaster. The international media also took a positive approach by focusing on the difficulties in disaster relief in the plateau area, the situation of ethnic minorities, and the various institutional mechanisms created and activated to provide support to the relief effort. In this regard, the Chinese government has become more sophisticated in handling public relations and information dissemination in the face of a catastrophe in order to highlight positively its major relief and reconstruction activities.

Quick planning for recovery and reconstruction: Based on the quick preliminary assessment of the disaster situation, the Chinese government promptly shifted its focus of work to recovery and reconstruction. After the 2008 Wenchuan Earthquake, the State Council issued the Regulation for Recovery and Reconstruction of the Wenchuan Earthquake (The State Council of the People's Republic of China 2008) which was the first regulation promulgated by the Chinese government for earthquake recovery and reconstruction. Within two months after the Yushu Earthquake, the State Council had already issued the Guidelines for Carrying out the PostDisaster Recovery and Reconstruction of the Yushu Earthquake (The State Council of the People's Republic of China 2010a) and approved the General Planning for the PostDisaster Recovery and Reconstruction of the Yushu Earthquake (The State Council of the People's Republic of China 
2010b), demonstrating the important role the government plays in disaster management.

Effective partner assistance model: The partner assistance model developed after the 2008 Wenchuan Earthquake proved successful in speeding up the recovery and reconstruction and ensuring its quality. Due to the special features of its geographic environment and climate, the disaster area of the Yushu Earthquake required an experienced professional assistance force to provide partner support. Therefore, the State Council of China selected Beijing Municipality, Liaoning Province, and four large state-owned enterprises for the partner assistance to Yushu. This model again proved to be invaluable in the recovery and reconstruction efforts after a major earthquake disaster.

\subsection{Lessons}

No response plan can be expected to perform perfectly in dealing with every aspect of a disaster. Thus each disaster event provides lessons that can improve future performance by refining the institutions and mechanisms employed to cope with disaster.

Underestimation of the special needs of ethnic minorities for relief goods: Tibetan culture contains special dietary requirements and habits of living that sustain local people's living in the disaster area. But China at present lacks the reserve of disaster relief goods for ethnic minorities, especially for Tibetans. Consequently, upon delivery to the disaster area, many of the livelihood necessities and foodstuff were not accepted by the earthquake victims, who for example would prefer to cook in the open air or in sheds instead of tents. But sheds for cooking were often unavailable. As a result, even in severe windy, rainy, or snowy weather, cooking and dining were often found done outdoors.

Underestimation of the difficulties for disaster relief in the hypoxia plateau area: Since the disaster area was located on high-altitude plateau, not only the processional rescue team members from low-altitude areas, but also the search and rescue dogs generally faced the problem of hypoxia reactions. Many of the rescue team members experienced the high-altitude reaction syndrome to various extents, while the performance of the search and rescue dogs was also affected. On 19 April 2010, the Guangdong rescue team of over 300 members, which was the first rescue team to arrive at Yushu, had to withdraw from the disaster area due to the high-altitude reaction. On the same day, six members of the Sichuan medical team got seriously sick due to the same problem. Many of the relief personnel involved in repairing infrastructure also suffered from the reaction and had to withdraw from the disaster area. These incidents indicate an insufficient special rescue force in adaptation to the high-altitude, hypoxia-prone environment and an underestimation of the difficulties encountered in rescue work in such regions.
Failure of the rescue force and relief goods to reach the disaster area promptly due to the relatively limited communication capacities: There are only three roads leading to the Jiegu Town of Yushu Prefecture and County. The first road is the north branch of the National Highway 214, the only passage from Xining to Yushu. Normally it takes at least 15 hours from Xining to reach the town. The entire route of this communication line is in high-altitude areas with adverse climatic conditions. The second road is the south branch of the National Highway 214 from Changdu in Tibet to Yushu, crossing various mountainous areas with dangerous road conditions. From Changdu to Yushu, the distance is over $500 \mathrm{~km}$, and it also requires more than ten hours to drive in good conditions. The third way to approach Yushu is from the Shiqu County of the Sichuan Province via Provincial Highway 307, a distance of $130 \mathrm{~km}$. But the Shiqu County is more than $1000 \mathrm{~km}$ away from Chengdu, the capital city of Sichuan Province. Therefore, it takes at least 10 hours for external rescue forces and disaster relief goods to reach the earthquake area. On the one hand, such conditions naturally delayed the external rescue forces attempting to reach the disaster area overland. On the other hand, high-altitude reaction also exhausted the rescue teams, thus reducing the effectiveness of the rescue effort. One exception is that the Batang Airport, a plateau branch airport just put into operation for the Yushu region, played a special role in transporting rescue teams and relief goods into the area and sending the injured for treatment and students for temporary schooling out of the area after the earthquake.

\section{Conclusions}

After the devastation of the Yushu Earthquake, China has learned many lessons and accumulated rich experiences in assessing disaster losses and responding to earthquake disaster in the special conditions of a remote high-altitude environment. These experiences and lessons can provide useful reference for high plateau earthquake response in the future. But these lessons indicate that much remains to be done in preventing and mitigating natural disasters of similar scale and under such severe environmental conditions.

\section{Acknowledgments}

This research is financially supported by the Fund Project: National Natural Science Foundation of China (NSFC), "Case Study on Core Science Projects of IHDP-IRG" (40821140354), Key Project of National Natural Science Foundation (91024024), Project of "11 $11^{\text {th }}$ Five-year" Science and Technology Support Program of the Ministry of Science and Technology (2008BAK49B0402), and the International Cooperation Project of the Ministry of Science and Technology: "Integrated Risk Governance-Model and Modeling" (2010DFB20880). 


\section{Notes}

i The 2008 Wenchuan Earthquake took place in Wenchuan County of Sichuan Province in China, causing 86 thousand causalities and USD 121.7 billion economic losses. It was the most devastating earthquake in China in more than three decades since the 1976 Tangshan Earthquake.

ii CEA (China Earthquake Administration). 2010. Field Survey and Assessment Report of Disaster Losses for the Yushu Earthquake (internal document).

iii NCDR (National Commission for Disaster Reduction). 2010. Technical Report on Remote-Sensing Monitoring and Assessment of the Yushu Earthquake (internal document).

\section{References}

Bai, L. P. 2010. The Exploration of Disaster Relief Socialization from the Experience in the Earthquake Relief. China Economist No. 2: 23-24 (in Chinese).

Chen, Y. H., Y. H. Ma, and X. X. Yang. 2010. The Seismic Anomalies of Yushu Ms 7.1 Earthquake and some Relevant Thought. Recent Developments in World Seismology 11 (383): 19-26 (in Chinese).

Deng, F., and J. F. Liu. 2011. The Government Emergency Preparedness Analysis from Response to the Yushu Earthquake. Journal of Beijing Normal University (Natural Science) (in press; in Chinese).

Ministry of Finance of the People's Republic of China. 2010. Notice for the Taxation Policies for Supporting the Post-Disaster Recovery and Reconstruction of the Yushu Earthquake. Beijing (in Chinese).

NCDR (National Commission for Disaster Reduction). 2008. Comprehensive Analysis of Earthquake Hazard Assessment. Beijing: Science Society Press (in Chinese).
Peng, H., X. M. Ma, and J. Q. Bai. 2006. Characteristics of Quaternary Activities of the Ganzê-Yushu Fault Zone. Journal of Geomechanics 9 (3): 295-304 (in Chinese).

People's Bank of China. 2010. Urgent Notice for Carrying Out Financial Services for the Disaster Areas of the Yushu Earthquake. Beijing (in Chinese).

Qian, X. D., and J. Z. Qin. 2010. 2010 Earthquake in Yushu, Qinghai Province and Strong Earthquake Trend Analysis of the Qinghai-Tibet Plateau after the Earthquake. Journal of Seismological Research 10 (33): 255-64 (in Chinese).

Ren, J. J., F. R. Xie, and D. Y. Liu. 2010. Study of Tectonics, Seismicity and Recurrence Interval of Yushu 2010 Earthquake, Qinghai Province 2010. Technology for Earthquake Disaster Prevention 6 (2): 228-33 (in Chinese).

The State Council of the People's Republic of China. 2008. Regulation for Recovery and Reconstruction of the Wenchuan Earthquake. Beijing (in Chinese).

The State Council of the People's Republic of China. 2010a. Guidelines for Carrying out the Post-Disaster Recovery and Reconstruction of the Yushu Earthquake. Beijing (in Chinese).

- 2010b. General Planning for the Post-Disaster Recovery and Reconstruction of the Yushu Earthquake. Beijing (in Chinese).

Wang, H. Y. 2010. Prediction of Acceleration Field of the 14 April 2010 Yushu Earthquake. Chinese Journal of Geophysics 10 (10): 2345-54 (in Chinese).

Wen, X. Z., X. W. Xu, and R. Z. Zheng. 2003. The Average Slip Rate of GanZi-YuShu Fault and Modern Earthquake Rupture. Science in China (Series D) 4 (33): 199-207 (in Chinese).

Xinhua News Agency. 2011. Reconstruction One Year after the Yushu Earthquake. April 14. http://www.qh.xinhuanet.com/yscj/2011-04/ 14/content 22519760.htm (in Chinese).

Xu, L. S., H. B. Di, and W. P. Feng. 2010. Estimation of the Fault-Near Ground Motion of the 2010 Yushu, Qinghai, Ms 7.1 Earthquake. Chinese Journal of Geophysics 6 (6): 1366-73 (in Chinese).

Open Access This article is distributed under the terms of the Creative Commons Attribution License which permits any use, distribution, and reproduction in any medium, provided the original author(s) and source are credited. 